\title{
Monitoring underwater explosions in the habitat of resident bottlenose dolphins
}

\author{
Manuel E. dos Santos ${ }^{a)}$ \\ Eco-Ethology Research Unit, ISPA—Instituto Universitário, Rua Jardim do Tabaco 34, Lisboa, P-1149-041, \\ Portugal \\ Miguel N. Couchinho and Ana Rita Luís \\ Projecto Delfim—Centro Português de Estudo dos Mamíferos Marinhos, Rua Alto do Duque 45, Lisboa, \\ P-1400-009, Portugal \\ Emanuel J. Gonçalves \\ Eco-Ethology Research Unit, ISPA—Instituto Universitário, Rua Jardim do Tabaco 34, Lisboa, P-1149-041, \\ Portugal
}

(Received 25 March 2010; revised 22 September 2010; accepted 6 October 2010)

\begin{abstract}
Maintenance work on the harbor of Setúbal, in Portugal, required the removal of a 14-m deep rocky outcrop at the ship maneuver area, using about $35 \mathrm{~kg}$ of Gelamonite, a nitroglycerin-based highexplosive. This important harbor is located in the Sado estuary, a biologically rich environment and an important feeding area for a resident community of bottlenose dolphins. Using different safe range calculation models, a mitigation and monitoring plan was developed that minimized the risks of these underwater explosions for the dolphins. At our monitoring station, at $2 \mathrm{~km}$ from the demolition site, acoustic pressure levels in excess of $170 \mathrm{~dB}$ re $1 \mu \mathrm{Pa}$ (root-mean-square) were measured. Samples of dead fish collected at the site were indicative of shock trauma from the blasts.
\end{abstract}

(C) 2010 Acoustical Society of America. [DOI: 10.1121/1.3506378]

PACS number(s): 43.80.Nd, 43.30.Lz [WWA]

Pages: $3805-3808$

\section{INTRODUCTION}

Among the sources of noise and disturbance increasingly produced by humans in the aquatic environments, explosions must be considered especially dangerous to marine mammals, because of the high energy level of the shock and acoustic waves they may generate in a very short time (Richardson et al., 1995; Finneran et al., 2000).

A chemical explosion is a rapid combustion reaction, in which the products fill a much greater volume than that occupied by the original materials, resulting in enormous pressures. Besides the transient acoustic waves, explosives form a gas sphere at high pressure and temperature, and a shock wave is radiated in the water (Chapman, 1985). Shock waves decay with increasing distance from their points of origin, gradually changing into ordinary sound waves, which may still be powerful enough to harm animals submerged in the fluid. The rapid pressure oscillation following an explosion engages their soft tissues, membranes, and cavities filled with air, causing blast trauma (Keevin and Hempen, 1997).

In the case of marine mammals caught by shock waves, the sudden increases in cerebrospinal fluid pressure may lead to brain damage, or they may present middle and inner ear damage, and also lung and intestinal hemorrhaging (see Ketten, 1995). Even the sound waves generated by explosions may have properties exceeding the ear's tolerance, namely their intensity, bandwidth, rise-time, or duration of peak pressure. The effects of sound waves, especially if permanent

\footnotetext{
a) Author to whom correspondence should be addressed. Electronic mail: manuel@ispa.pt
}

threshold shift is produced rather than temporary threshold shift, may be less obvious than blast shock trauma but equally serious, in the disruption of communication, breeding behavior, or navigation. However, the existing empirical knowledge regarding these threats to marine mammals is very limited, and it is still unclear whether they are more or less susceptible than terrestrial mammals.

As effects of explosions on fish, the rupture of various organs and membranes, especially swim bladders, has been studied in more detail, even experimentally (reviewed by Continental Shelf Associates, Inc., 2004), and explosives have commonly been used as a method of killing fish.

Explosions are often used in construction activities or in the removal of underwater structures and also by the military, in warfare, ship or weapon testing, in sinking retired ships, and other operations (Moore et al., 2006). Explosives were also commonly used in geophysical exploration, but they were replaced by airgun array pulses, which provide better source signatures (Hildebrand, 2005).

The harbor of Setúbal, Portugal, located in the lower estuary of the Sado river, serves the expansion of a growing industrial region. Ship safety concerns dictated the demolition of a rocky outcrop located at $38^{\circ} 30.911^{\prime} \mathrm{N}, 8^{\circ} 52.573^{\prime} \mathrm{W}$, at a depth of $14 \mathrm{~m}$, very close to the harbor walls (about $70 \mathrm{~m}$ ) in the ship maneuver area. This very hard rock proved unbreakable with traditional mechanical means, so the harbor administration was advised to blast it, and this operation took place on February 28, 2008.

Because of its richness in marine and estuarine life, the Sado estuary is used by a resident group of bottlenose dolphins (dos Santos and Lacerda, 1987; Gaspar, 2003; dos Santos 


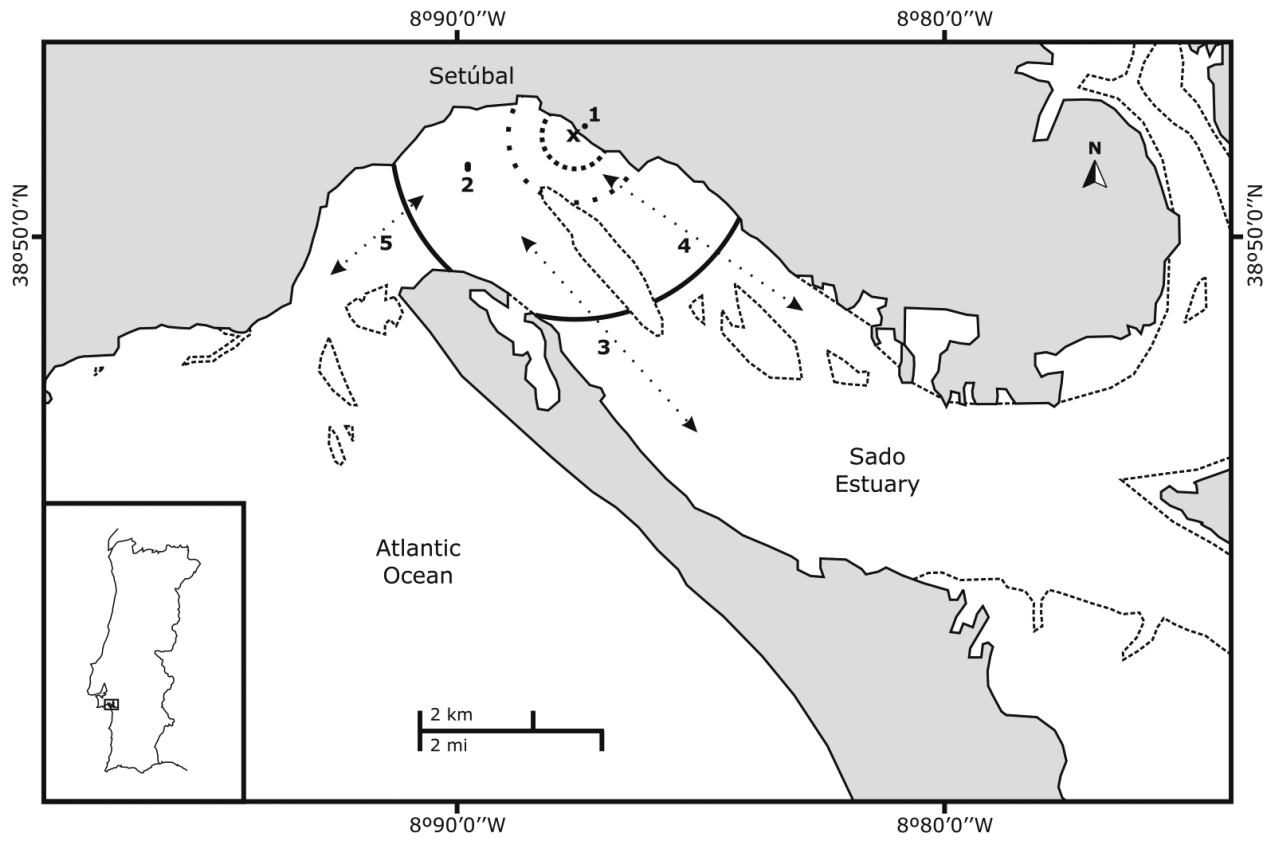

FIG. 1. The Sado estuary and the harbor of Setúbal, Portugal. X: The demolition site; inner circle: $596 \mathrm{~m}$; middle circle: $1192 \mathrm{~m}$; outer circle: 3270 m. 1: Land-based observer; 2: Measurement platform; 3, 4, 5: Boat observers.

et al., 2005, 2007). This dolphin community has been declining, numbering only 25 individuals. A difficult conservation scenario made the threat of any ill effect resulting from the demolition even more unacceptable to the authorities, so we were asked to develop and implement a mitigation plan, and this study of opportunity allowed us to carry out some measurements and to contribute to the protection of these animals.

\section{METHODS}

\section{A. Mitigation plan}

The first task was the definition of danger zones, which were calculated using the explosive loads stated in the demolition plan (provided by the local underwater services company Servisub, Almada, Portugal) and the appropriate propagation functions and coefficients (see below). The demolition plan rested on 38 charges (totaling $35.34 \mathrm{~kg}$ ) of Gelamonite 33 , a nitroglycerin-based high-explosive commonly used in mining, laid out in a grid at 1-m intervals. A sequence of three blasts was planned, separated by micro-delays. This would reduce the instantaneous shock but should actually enhance its demolition effectiveness.

The root-mean-square (rms) source level of the initial shock wave could be calculated using the formula of Urick (1975), with $w$ being the charge in pounds,

$$
\text { SPL dB re } 1 \mu \text { Pa at } 1 \mathrm{~m}=269 \mathrm{~dB}+7.53 \times \log _{10}(w),
$$

where SPL indicates sound pressure level.

An additional pressure resulting from the bubble pulse oscillations should be included in the value calculated (Hildebrand, 2005). In this case, if all the charges exploded simultaneously, the initial shock wave could be expected to reach at least $283 \mathrm{~dB}$ re $1 \mu \mathrm{Pa}$ at $1 \mathrm{~m}$.

To estimate the danger zone for dolphins, the distance function of Young (1991) for dolphin calves was used, as it is considered (e.g., Richardson and Malme, 1995) the most precautionary,

$$
R_{\mathrm{CP}}=578 w^{0.28},
$$

where $R_{\mathrm{CP}}$ is the safe range for calf porpoise in feet and $w$ is the charge weight in pounds.

The safety distance obtained, concerning the risk of injury, was thus $596 \mathrm{~m}$, considering the simultaneous blast of the 38 charges. Adopting the recommendation of O'Keeffe and Young (1984) of doubling the distance to reduce the risk of auditory impact, a safe range of $1192 \mathrm{~m}$ was calculated.

The calculation of a safe range for human swimmers was also legally necessary and appropriate since there are several beaches and nautical sports areas nearby. As there is a reasonable possibility that dolphins may be actually more susceptible to these explosions than humans and this is a dolphin community of special concern, we stipulated with extra precaution that the safe range for humans should be considered for the dolphins as well. To calculate it, the Portuguese Norm NP-2074 (issued in 1983) includes the following formula:

$$
R=\mathrm{CS} \sqrt[3]{Q}
$$

where $R$ is the safe range, CS is the safety coefficient for unprotected swimmers, and $Q$ is the explosive weight in kilograms (TNT-equivalent, or the same weight in Trinitrotoluene, which we adopted for simplicity). The distance calculated was then $3270 \mathrm{~m}$, and this was stipulated in our plan as the safe range for both humans and dolphin calves.

Then it was necessary to develop safety guidelines for the demolition, which included the following measures: (a) Introduction of warning blasts before the demolition, in a ramp-up procedure; (b) visual surveillance for the dolphins before and during the blasts, from one vantage point on land and four boats (Fig. 1); and (c) establishing a radio communication protocol for countdown abortion in case dolphins were detected approaching the danger zone.

The underwater services company was asked to introduce warning blasts (using detonation chord), with increasing noise at 3-min intervals starting 15 -min before the demolition sequences. 


\section{B. The demolition operation}

After sunrise, the zone of influence was surveilled visually by eight experienced observers from land using a 40-m high harbor porch platform and on water from our research launch Darwin and three other boats, which slowly crossed the whole lower estuary and the river mouth.

Detonation time was approached after several hours with no dolphin detection near the danger zone, so the countdown was initiated as scheduled. As countdown proceeded, the dolphins were detected entering the estuary, so the firing sequence was effectively aborted. After the dolphins were observed moving away to the adjacent coastal waters, more than $5 \mathrm{~km}$ from the demolition site, countdown was resumed.

With our boat at a distance of $2 \mathrm{~km}$ from the demolition site, acoustic measurements were carried out, using a calibrated recording system. A Cetacean Research Technology hydrophone, model C54XRS (sensitivity $-165 \mathrm{~dB}$ re $1 \mathrm{~V} / \mu \mathrm{Pa}$, frequency response: $0.008-203 \mathrm{kHz}(+2 /-20 \mathrm{~dB})$, powered by a $9 \mathrm{~V}$ battery), was lowered to $3 \mathrm{~m}$ below the surface. The nominal sensitivity includes the gain from the hydrophone's internal preamplifier. No anti-aliasing filter was used, and the hydrophone was connected by a $15-\mathrm{m}$ cable to a data acquisition board IOTECH PersonalDAQ 3005 digital interface (16-bit resolution and 1-MHz sampling rate). The recordings were made with a sampling rate of $200 \mathrm{kHz}$ to allow the analysis of data up to $100 \mathrm{kHz}$. Environmental acoustic background was characterized using a 30 -s recording just prior to the demolition.

The acoustic signals detected by the hydrophone were transferred in real time, directly through the analog-to-digital board, and recorded on the hard drive of the computer, using the acquisition software DAQVIEW 3.0. Analyses were performed using SPECTRALAB PRO 4.32-fast Fourier transform (FFT) spectral analysis system software (Sound Technology Inc.) with calibration presets adjusted to the hydrophone system, in sound pressure units, with flat frequency response between 97.66 and $97588.46 \mathrm{~Hz}$ and a spectral line resolution of $48.828 \mathrm{~Hz}$. The signals were analyzed using the FFT (4096 samples per segment), with a Hann smoothing window, an overlap of $50 \%$, and a time resolution of $6.83 \mathrm{~ms}$ per segment.

\section{RESULTS}

\section{A. Detonation recordings}

After a strong detonation, a radio communication indicated that some electrical misfiring had occurred, and only a part of the charges went off. The remaining charges had to be fired later. So, two different blasts were actually produced, separated by about half an hour, instead of the three near-simultaneous series. The SPLs received at our station exceeded $170 \mathrm{~dB}$ re $1 \mu \mathrm{Pa}$ (rms), which is the overload acoustic pressure of the hydrophone when powered with a 9 $\mathrm{V}$ battery. In fact, the measurements of the blasts reached 175 and $177 \mathrm{~dB}$ re $1 \mu \mathrm{Pa}$ (rms), but clipping effects were clear at the signal onset, precluding spectral analysis of the sound waves before the midsection of the signals. Nevertheless, the minimum estimated pressure level [170 dB re $1 \mu \mathrm{Pa}$ (rms)] is about $60 \mathrm{~dB}$ higher than ambient noise, therefore clearly audible to the dolphins.

In spite of our attempts to minimize the operation's biological damage, an estimated $200 \mathrm{~kg}$ of fish were found dead at the surface near the demolition site, especially from the columns underneath the harbor's main platform. Individuals collected at the site were representative of the local fish diversity-the white seabream Diplodus sargus, the goldline Sarpa salpa, the gray triggerfish Balistes capriscus, the sand smelt Atherina presbyter, mullets Liza spp, and the conger eel Conger conger. At the laboratory, necropsies of the 20 sampled individuals revealed external hemorrhages and internal lesions: Some cases of massive organ destruction, bleeding, rupture of the swimming bladder, and of internal membranes, which all typically result from shock waves.

\section{B. Follow-up}

The resident dolphins were sighted and tracked on two subsequent days, March 3 and 21, 2008, using our usual standardized techniques for the study of group composition, activities, and movement patterns. All known individuals were observed and photographically identified, with no apparent changes in their behavior, except one adult (labeled as TIP). This animal had been absent from the resident group for some time and in fact was not censused just prior to the demolition, but it was identified and observed in a subsequent survey (on June 20, 2008), with normal behavior and appearance. Our greatest concern was of course with the calves and the juveniles and apparently those were not at all affected by this demolition.

\section{DISCUSSION}

The safety plan and the procedures surrounding this demolition operation effectively avoided potential damage to the protected dolphins that share these waters with the harbor of Setúbal. The safety distances proposed by Young (1991) through Eq. (1) might not be as precautionary as generally supposed. If the animals had been at a distance of $596 \mathrm{~m}$ from the blast site and if all charges had fired simultaneously, a $283.2 \mathrm{~dB}$ re $1 \mu \mathrm{Pa}$ (rms) blast could be predicted, and the dolphins would have been exposed to pressures of $255 \mathrm{~dB}$ re $1 \mu \mathrm{Pa}(\mathrm{rms})$, above the $230 \mathrm{~dB}$ indicated by Southall et al. (2007) as high enough to cause hearing damage in the case of single pulses. Even doubling the safety distance to $1192 \mathrm{~m}$, the expected received levels [252 dB re $1 \mu \mathrm{Pa}$ (rms)] would have been well above the hearing damage levels. Even at the measuring distance of $2 \mathrm{~km}$, and in spite of partial misfires, the minimum pressure recorded was well above behavioral response thresholds for dolphins (Southall et al., 2007). We thus conclude that our decision to recommend the Portuguese Norm NP-2074 for humans [Eq. (3)] was in fact more precautionary.

Nevertheless, some aspects of this operation could naturally have been improved. Warning blasts were introduced in the demolition procedure but were not implemented in the unplanned second blast. Also, we did not anticipate that many fishes would hide in the palisade foundations of the 
harbor, and warning blasts should have been produced below the structure as well. Of particular concern, our acoustic data are minimum levels due to hydrophone saturation; it would have been preferable to measure farther away from the demolition site to obtain fair estimations of source levels, and the hydrophone must be carefully chosen and placed because of the sensitivity issues.

In summary, this demolition with explosives was not harmful to the dolphin community, although it was potentially very dangerous. Additionally, our inputs were awareness-raising to the local and national authorities concerned with the protection of marine mammals and to those involved in regional maritime operations.

\section{ACKNOWLEDGMENTS}

We thank the harbor authority of Setúbal (Administração dos Portos de Setúbal e Sesimbra) for the opportunity to monitor this event and especially the helpfulness of Ernesto Carneiro and Artur Pires. The Nature Conservation Institute (Instituto da Conservação da Natureza e da Biodiversidade) and the Sado Estuary Nature Reserve (Reserva Natural do Estuário do Sado) were also of great assistance. We are grateful to IMAR (Instituto do Mar, Faculdade de Ciências da Universidade de Lisboa) for the use of equipment and to Joe Olson for comments on our data. Our fellow observers on D-day were Sónia Louro, Joana Augusto, Patrícia Lopes, Cecília Ferreira, Helena Silva, Carlos Silva, and António Mourato and we appreciate their keen collaboration.

Chapman, N. R. (1985). "Measurement of the waveform parameters of shallow explosive charges," J. Acoust. Soc. Am. 78(2), 672-681.

Continental Shelf Associates, Inc. (2004). Explosive Removal of Offshore Structures-Information Synthesis Report (OCS Study MMS 2003-070, U.S. Department of the Interior, Minerals Management Service, Gulf of Mexico OCS Region, New Orleans, LA).

dos Santos, M. E., Coniglione, C., and Louro, S. (2007). "Feeding behaviour of the bottlenose dolphin, Tursiops truncatus (Montagu, 1821) in the Sado estuary, Portugal, and a review of its prey species," Rev. Bras. Zoociências 9(1), 31-40. dos Santos, M. E., and Lacerda, M. (1987). "Preliminary observations of the bottlenose dolphin (Tursiops truncatus) in the Sado Estuary (Portugal)," Aquat. Mamm. 13, 65-80.

dos Santos, M. E., Louro, S., Couchinho, M., and Brito, C. (2005). "Whistles of bottlenose dolphins (Tursiops truncatus) in the Sado Estuary, Portugal: Characteristics, production rates and long-term contour stability," Aquat. Mamm. 31(4), 453-462.

Finneran, J. J., Schlundt, C. E., Carder, D. A., Clark, J. A, Young, J. A., Gaspin, J. B., and Ridgway, S. H. (2000). "Auditory and behavioral responses of bottlenose dolphins (Tursiops truncatus) and a beluga whale (Delphinapterus leucas) to impulsive sounds resembling distant signatures of underwater explosions," J. Acoust. Soc. Am. 108(1), 417-431.

Gaspar, R. (2003). "Status of the resident bottlenose dolphin population in the Sado Estuary: Past, present and future," Ph.D. thesis, University of St. Andrews, UK.

Hildebrand, J. A. (2005). "Impacts of anthropogenic sound," in Marine Mammal Research: Conservation beyond Crisis, edited by J. E. Reynolds, W. F. Perrin, R. R. Reeves, S. Montgomery, and T. J. Ragen (The Johns Hopkins University Press, Baltimore, MD), pp. 101-124.

Keevin, T. M., and Hempen, G. L. (1997). The Environmental Effects of Underwater Explosions With Methods to Mitigate Impacts (U.S. Army Corps of Engineers, St. Louis, MO).

Ketten, D. R. (1995). "Estimates of blast injury and acoustic trauma zones for marine mammals from underwater explosions," in Sensory Systems of Aquatic Mammals, edited by R. A. Kastelein, J. A. Thomas, and P. E. Nachtigall (DeSpil Publishers, Woerden, The Netherlands), pp. 391-407.

Moore, K. C., Wells, R. S., Gannon, J. G., and Nowacek, D. P. (2006). "Responses of bottlenose dolphins to construction and demolition of coastal marine structures," Mote Marine Laboratory, Technical Report No. 1081.

O'Keeffe, D. J., and Young, G. A. (1984). Handbook on the Environmental Effects of Underwater Explosions (NSWC TR 83-240, Naval Surface Weapons Center, Dahlgren, VA and Silver Spring, MD).

Richardson, W. J., Greene C. R. G., Jr., Malme, C. I., and Thomson, D. H., editors. (1995). Marine Mammals and Noise (Academic Press, San Diego, CA), p. 576.

Richardson, W. J., and Malme, C. I. (1995). “Zones of noise influence," in Marine Mammals and Noise, edited by W. J. Richardson, C. R. G. Greene, Jr., C. I. Malme, and D. H. Thomson (Academic Press, San Diego, CA), pp. 325-386.

Southall, B. L., Bowles, A. E., Ellison, W. T., Finneran, J. J., Gentry, R. L., Greene C. R., Jr., Kastak, D., Ketten, D. R., Miller, J. H., Nachtigall, P. E., Richardson, W. J., Thomas, J. A., and Tyack, P. L. (2007). "Marine mammal noise exposure criteria: Initial scientific recommendations," Aquat. Mamm. 33(4), 411-522.

Urick, R. J. (1975). Principles of Underwater Sound (McGraw-Hill, New York), p. 320.

Young, G. A. (1991). Concise Methods of Predicting the Effects of Underwater Explosions on Marine Life (NAVSWC-MP-91-220, Naval Surface Weapons Center, Silver Spring, MD). 